\title{
Technologie verändert den Handel
}

Stationäre Händler kommen unter Druck. Umsätze und Flächenproduktivitäten nehmen in vielen Handelsorganisationen ab. Auch der Flächenbedarf geht zurück. Einstige Ikonen des stationären Handels, wie zum Beispiel Karstadt, Tesco, Media-Markt oder in jüngster Zeit sogar Wal-Mart, befinden sich mitten in einer Transformation.

Grund dafür ist die Digitalisierung unserer Wirtschaft und der damit aufkommende Online-Handel. Immer mehr Konsumenten informieren sich im Internet und präferieren den Online-Einkauf, was insbesondere für digitalisierbare Produkte wie Flugtickets, Musiktitel oder Bankdienstleistungen gilt.

Von diesem Wandel versuchen immer mehr Unternehmen zu profitieren. Stationäre Händler suchen den Weg ins Internet durch Cross-Channel Management. Hersteller drängen mit eigenen Verkaufsstellen (Monobrand-Stores) und eigenen Webshops in den Handel. Aber auch Online-Händler der ersten Stunde wie Amazon eröffnen „Flagship-Stores“ zwecks Markenstärkung. Zusätzlich kommen neue Handelsakteure in der nächsten Internetphase - dem Internet der Dinge - hinzu. So drucken Textildesigner ihre Kleider mit 3D-Druckern aus und verkaufen diese auf der eigenen Webseite. Das Internet der Dinge könnte etliche Distributionsketten revolutionieren.

Mit der damit einhergehenden Vernetzung unserer Internetgeräte beginnt ein neues Marketing-Zeitalter. Das Smartphone als ständiger Lebensbegleiter beschleunigt nicht nur den Online-Verkauf, sondern verändert auch das Handelsmarketing fundamental. Personalisierte Angebote mit hoher Kundenrelevanz basieren auf komplexen Big-Data-Analysen. Das neue „Online-Marketing“verspricht mehr Wirkung, weil insbesondere der Kommunikations-Zeitpunkt im so genannten „Customer Journey“ filigraner gesteuert werden kann:

In der Vorkaufphase inspiriert der Online-Newsletter, während am Point of Sale kommunizierte digitale Rabattcoupons den Kauf auslösen. Aber auch soziale Medien verlangen ein wirkungsvolles "Content Marketing" und damit neue Kompetenzen im Marketing der Zukunft.

Lesen Sie mehr in diesem Heft über neue Technologien, die den Handel verändern und das Marketing wirkungsvoller machen.

St. Gallen im April 2015

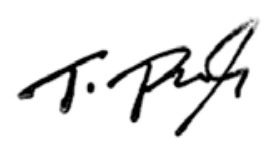

Prof. Dr. Thomas Rudolph 